\title{
Resenha
}

\section{TOJAL, J. Batista. Motricidade humana: o paradigma emergente. Campinas : UNICAMP, 1994}

A tese da Motricidade Humana (MH) é, não raras vezes, apresentada como alternativa para a assim chamada "crise da Educação Física (EF)". Para defender essa tese, o Prof ${ }^{\circ}$ Tojal realizou trabalho histórico-filosófico considerando, nos dois primeiros capítulos, acentuadamente históricos, a Unicamp, sua origem e posição atual na vida universitária brasileira, de forma a contextualizar a criação de sua Faculdade de Educação Física (FEF). Em seguida, situa o momento de criação da FEF, nos anos 80, como período de crise da EF mundial, levando a FEF a optar pela $\mathrm{MH}$ como uma dentre as alternativas que se colocavam enquanto elaborações teóricas capazes de justificar e garantir a existência da EF. Com a teoria da $\mathrm{MH}$, a FEF encontrava alternativa para sua crise de identidade e busca de uma matriz disciplinar norteadora de seu projeto curricular.

No capítulo terceiro, quando principia a parte marcadamente filosófica do estudo, Tojal observa e analisa o caminhar de Manoel Sérgio em direção à Ciência da $\mathrm{MH}(\mathrm{CMH})$, enfatizando o caráter eminentemente epistemológico desse caminhar. Apresenta uma visão geral do conjunto das obras iniciais e contemporâneas do filósofo português, bem como sua filiação às correntes epistemológicas francesas, sobretudo com Bachelard e Foucault, e ainda as fortes influências da Fenomenologia de Merleau-Ponty, da História da Ciência de Tomas S. Khun e do Estruturalismo de Althusser. É a partir dessas influências que Manoel Sérgio comporá o repertório de categorias que permitem caracterizar uma "problemática" ou "constelação de problemas específica da $\mathrm{MH}^{\prime}(\mathrm{p} .119)$ relativa tanto à Ergomotricidade (típica do trabalho) quanto à Ludomotricidade (típica das situações de jogo) e à Ludoergomotricidade (esporte de rendimento), com a qual se alcança o corte episte- mológico anunciador de uma nova ciência, a $\mathrm{MH}$, rompendo com o senso comum anterior, desarmado também de linguagem e procedimentos específicos, agora sintetizados nesse paradigma emergente. Esse representa "uma ruptura com a EF tradicional [pré-ciência da $\mathrm{MH}$ ], exclusivamente centrada nas áreas da saúde e educação e, como tal, vivendo analogicamente de Medicina e de Pedagogia, sem paradigma próprio" (ibidem).

Com isso a $\mathrm{MH}$ significaria o encontro de uma problemática disciplinar capaz de acolher um corpo de conhecimentos que explica seu campo fenomênico, bem como "a tendência geral do seu movimento", como elementos que, ao lado da aquisição de "uma nova linguagem", são indispensáveis "à constituição de uma nova ciência" com linguagem diferenciada das demais, a partir do objeto teórico de sua matriz disciplinar própria (p.125). Tojal apresenta, então, o glossário típico desse paradigma emergente e que lhe confere $o$ devido rigor acadêmico. Entre os termos, aparece a "educação motora ou corporal", definida como o ramo pedagógico da CMH (a qual busca compreender e explicar a conduta motora humana).

Para Tojal, o propósito maior de Manoel Sérgio foi conferir uma matriz teórica que possibilitasse à $\mathrm{EF}$, enquanto área do conhecimento, poder ser vista aos olhos de todos "como ciência autônoma", enfim, fazer da dança, do jogo, do esporte e da ginástica, p. ex., subsistemas de um sistema maior, $\mathrm{CMH}$, essa sim uma nova ciência do Homem superando a EF como seu estágio pré-científico. Manoel Sérgio dedicou-se, portanto, a conferir à EF "cientificidade e autonomia" (p.142); sua luta, conforme Tojal, foi em prol da racionalidade da EF. Para esta, Manoel Sérgio, com a teoria da $\mathrm{MH}$, procurou trazer 
a nova linguagem da filosofia pós-moderna desarticulando-a da razão instrumental, própria do pensamento moderno e que impõe à EF uma lógica cartesiana e reducionista.

No quarto e último capítulo, a CMH é finalmente abordada em sua operacionalização e adequação na conjuntura da FEF, enfim, trata-se da trajetória daquela Teoria nesta Faculdade. Nos anos de 1986/87, durante os debates acerca da reformulação curricular da FEF, tudo parecia convergir à "uma institucionalização da teoria já aceita" (p.154).

A partir da $\mathrm{MH}$ como matriz disciplinar, foram criadas duas grandes áreas de abrangência. A primeira denominada de conhecimento básico, buscava delimitar o objeto de estudo, padronizar a linguagem e o intercâmbio com as demais disciplinas científicas. A segunda visava ao conhecimento especializado da $\mathrm{MH}$ em situações de Recreação e Lazer, Esporte e Educação Formal. Em 1990, tal estrutura curricular já estava em vi gor: os alunos eram introduzidos à teoria da $\mathrm{MH}$ e, posteriormente, optavam pelo Bacha relado em uma área de especialização ou pela Licenciatura em EF.

Entretanto, pouco a pouco as discussões na FEF distanciavam-se da tese da $\mathrm{MH}$. Alguns docentes argumentavam que a $\mathrm{MH}$ ainda não conferia à EF uma teoria específica e carecia de "coerência interna" (p. 155). A MH anunciava o corte, mas não os critérios estruturadores de uma nova ciência. Tojal, então, refere-se a argumentos contrapostos e ao desconhecimento de muitos docentes relativamente à epistemologia da $\mathrm{CMH}$ como dificuldades que levaram a que "mudanças estruturais" fossem mais rápidas que "mudanças de atitude" (p.156).

Para Tojal, a $\mathrm{MH}$ permanece viva no cerne da FEF, mesmo não sendo posição hegemônica, tanto assim que: a) entre 1990 e 1991, das cinco teses de doutoramento de docentes da FEF, duas (FREIRE, 1991 e MOREIRA,1991) serviram-se com desenvoltura dos conceitos de Manoel Sérgio; b) a reformulação departamental privilegiou a tese da $\mathrm{MH}$, sobretudo entre os docentes do Dept ${ }^{\circ}$. de Educação Motora, cujo pré-requisito é o docente atuar no Laboratório de $\mathrm{MH}$; e c)
Tojal considera que também sua tese de doutoramento integra este momento em que trabalhos acadêmicos são produzidos tendo por referência a teoria da $\mathrm{MH}$.

Após esses três enfoques, é apresentada a visão de docentes da FEF a respeito da $\mathrm{MH}$ e suas perspectivas na FEF. Dez professores responderam um questionário. $\mathrm{O}$ autor apresenta as respostas, contudo, faz a opção de não analisá-las.

Em suas conclusões, o autor afirma ter buscado observar, mas não interferir, nos processos já completados ou em andamento na FEF, no que tange ao objetivo de sua pesquisa. Considera que existiu coerência nos estudos realizados na FEF sobre as bases epistemológicas da CMH. Contudo, tal não foi suficiente para que a compatibilidade inicial entre a teoria da $\mathrm{MH}$ e a FEF, expressa tanto no currículo, que segue princípios da $\mathrm{MH}$, como nas teses de doutorado citadas, fosse estendida à toda comunidade da FEF que ao contrário, mantém algumas resistências à $\mathrm{MH}$.

Conclui pela comprovação da aceitação da MH como matriz teórica de uma prática científica específica e pela identificação da FEF como o "lócus ideal para o surgimento de uma FMH" (p. 182) que assuma sua singularidade a partir do estudo do Homem em seu movimento de transcendência. $\mathrm{O}$ autor refere-se, também, à perspectiva de que a FEF, alcançando consenso entre seus membros em torno da CMH, seja o pólo irradiador de "uma Comunidade Científica, respeitante à $\mathrm{MH} "$ (p.182) no país.

Por fim, considera-se que a MH só pode ser entendida no seu sentido mais amplo na abertura que concede à transcendência, cuja auto-realização só é possível na superação solidária, para além das ortodoxias conservadoras ou progressistas, ambas presas a uma sociedade que muito produz mas não sabe distribuir; uma sociedade que afinal está errada, porque fundamenta-se numa concepção de Homem errada.

Em nossas considerações, vamos nos ater ao eixo central do estudo do Prof Tojal, a tese da CMH como proposta de uma nova 
ciência, pois, se não confirmadas as expectativas que rondam tal tese, ficam comprometidas as idéias sobre um paradigma emergente, bem como a proposta de um projeto curricular que a tenha por matriz disciplinar e, ainda, a possibilidade de se fundar, no país, uma $\mathrm{Fa}$ culdade da MH. Além disso, perde força a noção de que a crise da EF é uma crise de sua cientificidade.

Uma primeira reflexão é: como querer tornar a EF uma ciência, quando padrões, valores e referências tradicionais da ciência estão, como bem observado por Tojal, desmoronando e, ainda não alcançamos referências suficientes para um novo fazer científico nos seus mais diversos aspectos? Tojal credita a Manoel Sérgio o mérito de ter trazido à $\mathrm{EF}$, com a teoria da $\mathrm{MH}$, a nova linguagem da pós-modernidade. Essa 'nova' linguagem possibilitaria novos padrões, valores e referências a um novo fazer científico? Então o que é uma ciência pós-moderna?

Outra questão é por que a tese da $\mathrm{MH}$ é apontada como a melhor perspectiva de resolução da crise da EF se há outras sendo elaboradas nesse sentido, como Parlebas (1987) e Cagigal (1974) entre outros citados no estudo (e ainda haveriam mais)? Por que ela se constituiria enquanto superior às demais? Essa questão não fica bem respondida porque o autor apresenta, porém não discute os fundamentos epistemológicos da $\mathrm{MH}$ e, ainda, não os cruza com outras perspectivas, procedimento que, possivelmente, traria mais consistência à teoria da $\mathrm{MH}$, afinal uma perspectiva só pode tornar-se superior a outras quando confrontada com as concorrentes diante das quais demonstra maior consistência.

Outra reflexão é: qual a cientificidade da teoria da MH? Se, como quer Tomas Khun, a cientificidade é a vigência de um paradigma, então a $\mathrm{MH}$ encontra dificuldades para se afirmar como tal mesmo na FEF, onde não é posição hegemônica. Além disso, a cientificidade sob a vigência de um paradigma leva a que, na fase denominada de ciência normal, práticas teóricas e/ou experimentais sejam regidas segundo princípios do paradigma. Assim, entendendo que a $\mathrm{CMH}$ visa a compreender e explicar os fenômenos da conduta motora humana, então chegamos a um ponto de estrangulamento, ou seja, as condutas motoras podem ser compreendidas/ explicadas do ponto de vista da Psicologia, da Sociologia ou da Fisiologia e outras ciências afins. Como colocá-las sob o teto comum de princípios do paradigma sem ferir a lógica dos contextos epistêmicos próprios da Psicologia, da Sociologia ou da Fisiologia? Decorrem daí outras duas questões:

Primeira. É possível falar em um objeto teórico formal 'único', cujo campo fenomênico são as condutas motoras? Não seria aplicável à $\mathrm{CMH}$ a mesma crítica que Bracht (1993) dirige às pretensões de fazer do movimento humano o objeto científico da $\mathrm{EF}$, enfim, uma pretensa ciência do movimento humano? Esta sofre a crítica da impossibilidade de uma construção unívoca de tal objeto, posto que não temos um movimento humano, mas tantas quantas forem as abordagens que dele se faça a partir da condição epistemológica própria de cada disciplina que dele se ocupa. Enfim, a MH não dá conta de superar "o problema da fragmentação do conhecimento em torno do movimento humano [condutas motoras]" (p.115).

Segunda. Qual a filiação epistemológica que, afinal, adota a CMH? Suas práticas científicas orientar-se-iam pelas ciências naturais ou pelas ciências sociais e humanas? Como uma nova ciência do Homem, como postulado insistentemente por Manoel Sérgio, parece claro que seria a segunda a opção adotada. Mas, nesse caso, como ficariam, no interior, da $\mathrm{MH}$ disciplinas como a Fisiologia e a Biomecânica, cuja lógica nos remete àquele primeiro âmbito científico?

Uma terceira reflexão indaga sobre a própria racionalidade do conhecimento sob esse paradigma emergente. Nesse sentido, Tojal não poupa críticas à Razão Instrumental e seu reducionismo cartesiano, indicando que o velho justificacionismo que "afirmava só ser científico o que pudesse ser provado, o que fosse positivamente demonstrado pela argumentação de fatos repetidamente observados" caducou (Silva e Pinto, 1989 apud Tojal, 1994, p. 162). De fato, a partir de Manoel Sérgio, Morin Ü984), Souza Santos (1989) e outros autores de perspectiva filosófica pósmoderna, Tojal capta a mudança de paradig- 
ma na filosofia e suas pretensões de verdade. Não mais a filosofia da consciência e sim a da linguagem forneceria elementos centrais para uma pretensão de verdade baseada em argumentos. O autor, contudo, não explicita qual a racionalidade orientadora da cientificidade da teoria da $\mathrm{MH}$.

Assim, considerando estudos de Oliva (1990) e Bombassaro (1992), há duas principais concepções na filosofia da ciência. Uma 'tradicional', englobando Francis Bacon, o Círculo de Viena e K. Popper; outra 'nova', incluindo Paul Feyerabend, Tomas S. Khun e Habermas. Aquela basearia a cientificidade em critérios como o observacionismo e $\mathrm{o}$ indutivismo (Bacon) ou o falseacionismo (Popper), e esta, sobretudo com Feyerabend e Khun, valorizaria a história da ciência e não critérios propriamente. Então, de acordo com Bombassaro (1992), podemos considerar uma concepção criterial de racionalidade, vinculada a uma filosofia tradicional da ciência; e outra a-criterial, respeitante à nova filosofia da ciência; existindo ainda uma terceira concepção (a partir de Habermas e Putnam) a racionalidade como aceitabilidade racional, baseada no paradigma da comunicação e entendendo a razão como resultado do discurso.

É verdade que Tojal, ao discorrer sobre a CMH, foge aos padrões de uma racionalidade fixa e imutável. Por outro lado, não explicita uma alternativa que o faça não cair no pólo oposto, uma racionalidade a-criterial, i.e., no relativismo. Tal idéia é reforçada quando o autor se propõe a operar com categorias chave da proposta de cientificidade de Khun. Além disso, não chega à proposta de Habermas e Apel ou ainda Putnan, que tem sido, freqüentemente, colocada como uma alternativa quando se discute a necessidade de existir uma racionalidade que não seja ahistórica, fixa e imutável, nem relativista a ponto de não conter qualquer normatização.

$\mathrm{Na}$ verdade, perguntamos pela racionalidade na $\mathrm{CMH}$ porque ela traria à $\mathrm{EF}$ a nova linguagem pós-moderna. Ocorre que, para Tojal, isso significa considerar que a modernidade findou "em qualquer de seus aspectos essenciais", logo, aí vai inclusa a idéia da razão, algo central no pensamento iluminista, berço do pensamento moderno. Assim, que os sinos dobram pela razão instrumental é fato inconsteste (e caro aos positivistas), porém, fazer da crise do pensamento moderno a crise da razão humana é beirar o irracionalismo. Uma alternativa em voga é reconstruir a razão humana sob uma ética que supera a instrumentalização que privilegia interesses tecnocráticos. No entanto, Tojal concorda que "Iluministas, Hegel, Marx; positivistas e historicistas de todos os tipos pensavam da mesma maneira: que o sentido da história fosse a realização da civilização, i.e., da forma do homem europeu moderno" (p.61). Esquece, todavia, que, desses, foi Marx o único a proclamar abertamente a necessidade de experimentarmos o desenvolvimento/progresso fora do regime capitalista. Portanto, como seria o sentido da história humana numa comunidade autenticamente humana ou sem explorados e exploradores? Será que, sem o jogo do poder entre as nações modernas, com a hegemonia do primeiro mundo (países capitalistas centrais), haveria a noção de "europeu moderno" como a melhor forma de humanidade (ibidem)? Seria possível tal idéia manter-se se aos "europeus modernos" não fosse permitido, como o faz o mercado capitalista internacional, apropriar-se de recursos e tecnologia e ainda torná-los não disponíveis, p. ex., à Ảfrica e à América Latina?

Para Tojal, o Colonialismo e o Imperialismo chegaram ao fim tanto quanto a "dissolução da idéia de história" como fatos que atestam o colapso da modernidade e o "advento da sociedade da comunicação" (p.60). Afinal, o que é tal sociedade: é capitalista ou socialista, ou retomamos à melhor tradição idealista que pensa poder mudar o mundo existente mudando as frases deste mundo? Tojal fala também em "sociedade transparente" (idem), e a define como sociedade pós-moderna na qual os mass media exercem papel decisivo. Seria uma sociedade na qual os meios de comunicação forjam a "simulação da experiência" com imagens que "não refletem, mas sim formam a realidade" (Cal-linicos, 1992,p.22)? Mas, afinal, a serviço do que ou de quem? Enfim, uma sociedade mais complexa e "caótica"em cujo "caos" residiriam nossa esperança de emancipação. Aqui uma crítica a esperança de emancipação pós-moderna é análoga à uma de um movimento do Homem rumo à transcendência como uma idéia-chave na CMH. Lembremo-nos: "Não há transcendência se as 
cadeias que aprisionam os homens num vale de lágrimas não forem rompidas" (Carvalho, 1994,p.118). Na interpretação de Tojal, a teoria da $\mathrm{MH}$, numa postura positivista, escamoteia que, sob a forma capitalista de existência social, os homens não podem ir além da condição de se tomar ou 'mercadorias' ou capitalistas. Para além disso, só uma "transcendência" metafísica e irreal, ahistórica.

A última e quarta reflexão refere-se à proposta de tornar a EF ramo pedagógico da CMH sob a denominação de Educação Motora ou Corporal. Em que esta se diferencia daquela em termos de conteúdos, objetivos e metodologia de ensino? Como a CMH pode responder satisfatoriamente a pergunta "o que é EF"? A existência de tal ramo pedagógico dependerá da resposta obtida.

Entre as propostas de entendimento da EF, figuram três: ciência, profissão e disciplina do currículo escolar. A primeira perspectiva ainda não se firmou. Quanto às outras duas, Bracht (1992) propõe que, num sentido restrito, a EF assume o estatuto de atividade pedagógica vinculada à instituição educacional e tematizando elementos da cultura corporal/de movimento. Como profissão ou num sentido amplo, a "EF" incluiria todas as manifestações culturais ligadas à ludoergomotricidade. Todavia, o conjunto de possíveis atividades de quem exerce a profissão "EF" diferencia-se da EF (sentido restrito). Aquele profissional pode, p. ex., exercer atividades na instituição esportiva ou reabilitação fisoterápica.

Dessa forma, é difícil compreender como a MH poderia abranger todo esse campo fenomênico (Ludoergomotricidade) compreendendo-o/explicando-o sob uma ótica ci- entífica levada à escola como Educação Motora. Sabe-se que a EF, para levar à escola o movimento humano que tematiza, serve-se das mais distintas disciplinas e ciências afins, tais como Fisiologia e Sociologia, que, aliás, servem ao propósito de compreender/explicar os fenômenos da Ludoergomotricidade, de forma que não fica visível como a CMH superaria esse procedimento até então 'tradicional'.

Segundo pensamos, ainda não se confirmaram as expectativas em torno da fundação dessa nova ciência. Assim, fica comprometida a tese da emergência desse novo paradigma, bem como de seus sucedâneos.

\section{REFERÊNCIAS BIBLIOGRÁFICAS}

BOMBASSARO, L. C. As fronteiras da epistemologia. São Paulo : Vozes, 2. ed.,1992.

BRACHT,Valter. Fducação Física e aprendizagem social. Porto Alegre: Magister, 1992.

Educação Física/Ciências do Esporte: que ci ência é essa? Revista Brasileira de Ciên cias do Esporte, 14 (1), 1993.

CALLINICOS, Alex . O marxismo e as revoluções do leste europeu. Rio de Janeiro: Jorge Zahar, 1992.

CARVALHO, Máuri de. O corpo e o filósofo: temas proibidos. Vitória : UFES, 1994.

OLIVA, Alberto. Epistemologia: a cientificidade em questão. São Paulo : Papirus, 1990.

Por:

Marcelo Guina Ferreira Valter Bracht 